\title{
Enhancing place-based learning progression through epistemic agency: a response to toward a hypothetical place-based learning progression for haze pollution in the northern region of Thailand
}

\author{
Lezly Taylor $^{1} \cdot$ Brenda Brand $^{1}$
}

Received: 14 August 2020 / Accepted: 26 January 2021 / Published online: 12 May 2021

(c) The Author(s), under exclusive licence to Springer Nature B.V. 2021, corrected publication 2021

\begin{abstract}
Luecha Ladachart, Manus Poothawee, and Ladapa Ladachart take a unique approach in their study entitled, "Toward a hypothetical place-based learning progression for haze pollution in the northern region of Thailand," whereby they frame acquiring disciplinary knowledge within a place-based learning progression in response to regional issues related to air pollution. From this study, the authors created a proposed learning progression that was designed to facilitate an understanding of the cause and effect of haze pollution as it relates to anthropogenic issues, geographical location, and seasonal patterns distinctly for the northern region of Thailand. The purpose of this response article is to discuss the design of Ladachart, Poothawee, and Ladachart's (2020) place-based learning progressions and to facilitate a discussion on enhancing place-based learning progressions through the development of identity, self-efficacy, and epistemic agency. Lastly, we will reflect on our research in the Mississippi Delta (USA) to engage a discussion on how anchoring learning progressions across epistemological dimensions enables students to advance cognitively and developmentally while experiencing the personal and social transformation that positions them as epistemic agents within their local communities.
\end{abstract}

Keywords Epistemic agency $\cdot$ Science identity $\cdot$ Self-efficacy

Lead editor: G. Glasson

This review essay addresses issues raised in Luecha Ladachart, Manus Poothawee, and Ladapa Ladachart (2020) entitled, Toward a hypothetical place-based learning progression for haze pollution in the northern region of Thailand (doi: https://doi.org/10.1007/s11422-020-09981-9).

Lezly Taylor

lezly8@vt.edu

Brenda Brand

bbrand@vt.edu

1 School of Education, Virginia Polytechnic Institute and State University, Public Safety Building, Suite 201 (0313), 330 Sterrett Drive, Blacksburg, VA 24061, USA 
The framework for K-12 science education has undergone several reformations to ensure that students acquire disciplinary knowledge as well as engage in science practices that reflect scientific literacy and civic responsibility (NGSS Lead States 2013). Although such reformations have revolutionized how science is taught in the twenty-first century, shifting perspectives continue to arise regarding how to effectively design socially relevant curriculum that includes participatory and practice-oriented dimensions of science that support the development of science literacy (Kelly 2011). Ladachart et al. (2020) take a unique approach in their study entitled, "Toward a hypothetical place-based learning progression for haze pollution in the northern region of Thailand," whereby they frame acquiring disciplinary knowledge within a place-based learning progression in response to regional issues related to air pollution. From this study, the authors created a proposed learning progression that was designed to facilitate an understanding of the cause and effect of haze pollution as it relates to anthropogenic issues, geographical location, and seasonal patterns distinctly for the northern region of Thailand. Learning progressions are widely recognized for enhancing conceptual understanding but continue to evolve as researchers contextualize progressions within place-based curricula (Larsen and Harrington 2018). Gregory Smith notes the beneficial aspects of place-based education in stating, "The opportunity to participate in learning activities that focus on real-world problem-solving can impart to children a sense of their own agency and collective capacity to alter their neighborhoods or communities for the better" (Smith et al. 2007, Lead, p.192). Integrating place-based education within learning progressions is a transformative vehicle for developing conceptual understanding of science topics, science literacy, and meaningful participation within local communities. Ladachart et al. grounded their proposed learning progression in conceptual understanding; however, integrating place-based education within learning progressions requires students to engage in participatory agency with the local community. We propose that place-based learning progressions can be enhanced to address epistemic agency, which strategically structures students' participation, identity development, and self-efficacy as a part of the sequenced progression. We will reflect on our research in the Mississippi Delta (USA) to engage a discussion on how anchoring learning progressions across epistemological dimensions enables students to advance their conceptual understanding of science and engineering practices while experiencing the personal and social transformation that positions them as epistemic agents within their local communities.

\section{Review of place-based learning progression in Thailand}

Although complexities regarding pollution are typically addressed within standard science curricula, they are often presented from a global and universal perspective that generalizes the causes and effects. In their study, Ladachart et al. depart from the universal approach to present the multidimensional nature of haze pollution as it relates to the social, economic, and political context of the northern region of Thailand. The northern region of Thailand has an extensive heritage of rice farming that has evolved into an agricultural industry with rice and corn as staple crops. Mass production within the agricultural industry has led to economic development along with the mass production of biowaste. Historically, biowaste management was resolved by the cultural practices of burning; however, the continued practice of burning on the modern agricultural scale has led to mass production of haze pollution. Some of the residents in this region burn biowaste as a means of producing heat during colder seasons, while others believe this ancient practice to be necessary for the cultivation of the land 
for crop production. The environmental challenges of pollution in that area are coupled with rapid urbanization because of the expanding tourism economy. The developing infrastructure due to urbanization comes at the price of compromising the environmental integrity of the land. The geographical positioning of this region in terms of the air pressure, seasons, and the mountains makes this area highly vulnerable to pollutants collecting in the air forming a thick haze. Although governmental organizations have noted the significance of this environmental issue and created policies to regulate the burning of biowaste, these regulations have not had much effect on cultural practices of burning or pollution. Ladachart et al. suggest that including students' prior knowledge and understandings of haze pollution through the application of place-based learning progressions may influence cultural practices of burning in the future while providing classrooms as adequate spaces to create sustainable solutions for reducing and eradicating haze pollution in the northern region of Thailand.

Ladachart et al. purposefully fuse the element of place-based education with learning progressions as a strategy for motivating students to examine the reciprocating influence of science and human behavior, both geographically and culturally. Learning progressions enable educators to determine and design specific learning targets to conceptually advance students' content knowledge and science practices across grade levels. The construction of the authors' proposed place-based learning progression was the result of several analytical interactions of qualitative surveys and interviews. Ladachart et al. developed a questionnaire to assess a group of students' general understanding of haze pollution within the context of their placebased experiences. The authors then analyzed qualitative responses from the questionnaire to construct a tentative place-based learning progression that was later revised based on semistructured interviews from the second group of students ranging from seventh grade to twelfth grade. The authors stratified learning objectives across four progression levels in which the learning target centered on the cause and effects of haze pollution in relation to the seasons, air pressure, landscape, and geographical location. Within the learning progression, students understand how particulates form from burning and how the geographical and atmospheric conditions contribute to the formation of haze. Throughout the learning progression, students' prior knowledge and experiences are assessed in relation to their understandings of their scientific explanations. At the highest level of the proposed learning progression, students have the ability to communicate a conceptually sophisticated answer based on connecting scientific evidence to community practices regarding how haze pollution occurs. According to the authors, as students understand how human behaviors contribute to haze pollution, they will then be able participate in designing sustainable solutions to mitigate and or eradicate haze pollution. While learning progressions that emphasize conceptual knowledge are essential, researchers have recently shifted the utility of such progressions to include the design of practice-oriented learning progressions (Pierson et al. 2019). Ashlyn Pierson, Douglas Clark, and Gregory Kelly assert that "....authentic engagement in science practices involves more than the replication of professional practices in K-12 contexts" and that "Meaningful engagement in science practices requires that students be positioned as epistemic agents.." in which students appropriate the knowledge, skills, and practices of science as tools of inquiry (Pierson et al. 2019, p.833). 


\section{Expanding place-based learning progressions to address epistemic agency}

Place-based education uses the local community as a performative place to use the tools of science to solve local problems. David Sobel states place-based education “...increases academic achievement, helps students develop stronger ties to their communities, enhances students' appreciation for the natural world, and creates a heightened commitment to serving as active, contributing citizens" (Sobel 2004, p. 4). Essentially, the goals of place-based education center on agency, environmental responsibility, and ownership. Thus, placebased learning requires the students to engage in epistemic agency, in which the students may regard themselves as scientists that are capable of creating knowledge, regulating how knowledge is utilized within the local community, and regard themselves as responsible for the creation and enactment of solutions in science (Eglin 2013). The construction of a science identity is conceptually complex as it subsumes a multiplicity of other social and cultural identities; however, the science identity transformation affords students a sense of efficacy when using the tools of science (Avraamidou 2020). In this sense, students possess the autonomy to construct new knowledge in their local place using science practices. While Ladachart et al.'s effectively noted that the long-term goal is to impact human behavior with respect to creating haze pollution in the northern region of Thailand, their focus was primarily on conceptual knowledge, which alone does not cultivate or ensure human responsibility or epistemic agency. Thus, in the design of place-based learning progressions, how can epistemic agency be actualized? In addition, if epistemic agency involves students participating as scientists in their local community, what experiences are needed to facilitate the transformation of a science identity that provokes them to reconceptualize their capacity to become agents of change in their communities? Such questions provide an opportunity to expand learning targets within place-based learning progressions.

Beyond simply advancing content knowledge, learning progressions offer opportunities for cognitive development across anchors by addressing epistemic practices. Thomas Corcoran et al. (2009) note that "engaging in complex cognitive tasks such as inquiry, argumentation, and explanation," which are epistemic processes, are fundamental to developing a sophisticated understanding of science as well as demonstrating scientific practices (p.12). They further assert that the path of cognitive development for students is not "purely incremental" rather that such development occurs over time across increasingly complex schemes or progressions that are modified as students encounter new experiences (Corcoran et al. 2009, p.18). Thus, epistemic practices serve as learning targets within learning progressions that map students' cognitive development. Practice-oriented learning progressions that address epistemic aims are intended to move students away from being mere technicians in which students perform rote confirmatory science (Stroupe et al. 2018). Grounding the progression of learning through epistemic agency encourages full participation in the construction of knowledge and solutions through scientific habits of mind (Stroupe et al. 2018).

Pierson et al. (2019) argue that conceptually based learning progressions and practiceoriented progressions alone are not sufficient to authentically engage students in science learning. Instead, through examination of various studies, Pierson et al. (2019) urge educational researchers to both consider and imagine how to design experiences within learning progressions that advance the development of disciplinary identities as they develop cognitively. In similar fashion prior, Michalinos Zembylas (2005) argues the necessity of creating learning experiences that parallel the progression of cognitive development with 
the progression of the affective state of students, "particularly involving emotions, motivation and social aspects, such as group work, and learner characteristics, such as students' self-efficacy and...beliefs" (Duit and Treagust 2012, p110). Zembylas arguments are congruent with Bandura's (1994) sociocultural learning theory that notes that learning is driven by the reciprocal relationship between internal characteristics such as self-efficacy and external experiences (Bryan et al. 2011). Horn (2008) found that disciplinary identities influence persistence and achievement as students engage in learning. Pierson et al. (2019) assert that future learning progressions research should “...consider not only what is traditionally framed as disciplinary knowledge, but also equally important constructs like identity and community in order to support students' development of and engagement in meaningful science practices" (p. 839).

Furthermore, embedded within exploring factors that influence epistemic aims are notions of positionality as it relates to identity as well as sociocultural and sociopolitical factors that influence the production of knowledge (Yucel 2018). Navigating personal beliefs and social constructs regarding identities and efficacy concerning producing knowledge is significant (Hofer 2006) in the process of students developing science identities in which they take ownership of disciplinary knowledge beyond the spatial dimensions of the classroom and the temporal dimension of conceptual learning progressions (Córdova and Balcerzak 2016). For students to act as agents, in which they take ownership of sciencerelated issues in their community, educators must strategically create opportunities for participation within science communities and local communities. As students shift from a passive position of acquiring knowledge in the classroom to an active practice of science in and out of the classroom, students will encounter systems and structures that influence their participation (Miller et al. 2018).

Ladachart et al. contribute to the body of research that discusses the reformation of conceptually based learning progressions in science by including place-based knowledge. We posit that the research of Ladachart et al. could be enhanced through a discussion of how enacting change in the region is actualized through epistemic development which prioritizes students' ownership in their role as scientists as a result of engaging in action-oriented practices. What could be further developed in the Ladachart et al. study is examining how existing structures in the northern region of Thailand structure the participation of students and the local communities. Upon further examination of this study, how can opportunities be created to negotiate a science identity and enhance self-efficacy while empowering their cultural identity? In the following sections, we will discuss a place-based STEM learning progression designed to develop students' epistemic agency through the enhancement of their science identity and self-efficacy as they were engaged in applying science and engineering practices in solving local problems.

\section{Actualizing STEM potential program}

Sociopolitical, sociocultural, and socioeconomic macrostructures of inequality stratify communities regarding epistemological participation within the scientific disciplines and STEM-related fields. Aligned with Dewey's notion of equitable participation (Williams 2017), we designed a program, "Actualizing STEM Potential in the Mississippi Delta" (ASP), in response to systemic barriers for African-American students in STEM. This program, sponsored by the National Science Foundation (NSF proposal no. 1511792), serves high school students in grades 9-12 in an underserved, predominantly 
African-American school district in the Mississippi Delta, where a marginal percentage of the students pursue STEM careers, and an even smaller percentage persist after entering college. The school district where the program is implemented is under resourced with few science classes and AP courses, and hardly any initiatives to inspire students' career goals in STEM fields; thus, students have limited opportunity and cultural capital for developing an identity in STEM (Bourdieu 1986). The ASP program is grounded in practice-oriented learning with equitable access to resources which is fundamental to students constructing knowledge in science and engineering. Beyond focusing exclusively on conceptual development, our goals that center participation were developed out of Albert Bandura's (1994) concept of self-efficacy which "...posits that bidirectional interaction between personal factors, behavior, and external environment are paramount to achievement" (Flowers et al. 2019, p.139). This bidirectional interaction is a key factor in the ontological transformation of the self, represented as identity, and is cultivated through epistemological development which progresses learning through practice-oriented experiences. Therefore, the goal of constructing an identity and influencing self-efficacy is key to students' development of epistemic agency leading to their active participation within their local community of place.

Developing scientific literacy, which is foundational to place-based education, is touted as the benchmark of education reform which prioritizes students using the tools of science as they participate in civic, cultural, and economic affairs. David Gruenewald affirmed the significance of science literacy in stating: "Place-based pedagogies are needed so that the education of citizens might have some direct bearing on the wellbeing of the social and ecological places people actually inhabit" (Gruenewald 2008, p.308). Gruenewald also noted place-based education must go beyond the constructivist approach of experiential- and community-based learning to examining how the local environment and members of that environment were shaped by power dynamics and hegemonic structures. Although place-based education prioritizes experiential learning and ownership, we argue that fostering ownership of science is not possible without addressing internalized and external social constructs and hegemonic structures that alienate marginalized students from practicing science with efficacy and agency in their local communities.

Inequitable access to science- and STEM-related courses, corresponding resources, and STEM-based programs not only yields inequitable participation within the scientific and technological enterprise (Lancaster and Xu 2017) but also robs local communities from cultivating economic, social, and cultural capital from representatives of that place (Bourdieu 1986). In addition, the ability for African-American students to authentically engage in science communities of practice has been marred by negative stereotypes deriving from a racial epistemology that renders minorities as inferior and incapable of knowledge construction and contributions within science- and STEM-related disciplines (Lynn 2004). An internalization of racial epistemologies can negatively influence students' authentic engagement and participation in science and STEM as it relates to their communities of place. Such internalization is reflected in documented studies that depict perceptions of predominant profiles of scientists as white males while also depicting a dissociation and disidentification of their own identities as scientists (Smith et al. 2007). Research also notes the socioeconomic and sociopolitical structures in education that earmark and reserve STEM education for privileged and dominant communities contribute to the scientific disidentification for African-American students and a decline in their effort to pursue a scientific career (Woodcock et al. 2012). As Ladachart et al. displayed in their study, science-related issues are not universal, and the participation and practice of science itself 
within each community of place intersect with a myriad of factors that require distinct learning progressions.

The ASP program has an epistemological focus aligned with A Framework for K12 Science Education (Zembylas 2005) emphasizing explicit integration of engineering practices and design-based solutions in science learning. The Framework emphasized these two elements "because they provide students a place to practice the application of their understanding of science, and because the design process is an important way for K-12 students to develop an understanding of engineering as a discipline and as a possible career path" (Damsa et al. 2010, p. 27). In response to recommendations prescribed by Hutchison-Green (2008), the preengineering curriculum is explicitly designed to allow students to demonstrate science practices while engaging them in relevant and current engineering applications. Many researchers in the field of science education converge on the importance of students engaging in science practices and shaping knowledge, but discussions arise when determining how to effectively create opportunities for students to engage in epistemic agency (Miller et al. 2018). The ASP program was designed to intentionally engage students in inquiry whereby they can discover meanings while discovering the tools of science. Inquiry-based instruction is instrumental in establishing autonomy and identity construction by positioning the student as one who constructs knowledge through the engagement of practices. Miller et al. suggest that epistemic agency is fostered through practice-oriented learning that is "designed to both disrupt students' images of school science and to provide them with a new vision of who they could be as scientists" (Zembylas 2005, p.1195). The ASP program has a curricular focus on engineering in which students encounter disciplinary knowledge, methods and processes of the engineering discipline, and practices for epistemological understanding. The vast majority of students had no prior experience with engineering, nor publicized images representing their positionality in engineering fields; thus, their self-efficacy during these experiences was of interest. Further, engaging students in engineering inquiry as a of means of identity development that is aligned with Bandura's (1994) social cognitive theory was also explored, including the perceptions that individuals held about their abilities to fulfill certain tasks to achieve desired outcomes. Our objective was to examine how self-efficacy and science identity were influenced as students progressed toward epistemic agency within their community of place.

\section{Methodological approach}

Our objective was to design a learning progression to cultivate epistemic agency in which students are positioned to construct knowledge and influence practices of that knowledge within their community. The ownership and regulation of knowledge and corresponding practices that are associated with epistemic agency can be examined through the development of a science identity in which students may see themselves as a scientist and or engineers. Students' self-efficacy would also be enhanced if they believe that they have the epistemic capacity to engage in disciplinary practices and master the tasks associated with practicing scientist or engineers. The aims of our study echo David Stroupe's (2014) perspective on current educational reform objectives in which he states, "that students, in addition to learning concepts and methods, should become legitimate participants in the social, epistemic, and material dimensions of science" (p. 488). The goals of this learning progression were twofold. The first goal of the learning progression was to explicitly monitor and assess students as they developed in 
their science identity and self-efficacy while increasing their understanding of the engineering design process through the application of engineering practices to real-world problems. The second goal was to enhance student participation through the construction of a science identity and development of efficacy regarding engineering so that students can function as agents of change within their communities. The design of each anchor in the learning progression was aligned with Kobrin et al. (2015) discussion of how the anchors should progress students in addressing preconceptions in the first or entry anchor, provide an intermediate level for cognitive and conceptual development, and determine explicit objectives that demonstrate that learning has occurred within the last anchor. In addition to conceptual development, we used a bottom-up approach to look at the progression of participation in engineering practices and the development of epistemic agency within the community.

In accordance with Duschl et al. (2011), the selection of topics and overall arrangement of content is based on the instructors' iterative assessment and analysis of how students progressed across content and themes in science. The ASP program is a longitudinal mixed methods case study that is in its fifth year. The curricular design of the learning progression was the result of measuring students' science identity and self-efficacy as they participated in engineering practices across each year of the program. Qualitatively open-ended interviews were conducted annually with students to assess changes in orientation toward science, self-efficacy, participation, and epistemic agency in place. Margaret Heritage (2008) notes that when using the bottom-up approach both educators and experts design specific learning progressions in response to their experiences with students during their learning over time. Thus, our collaborative team of local scientist, educators, and researchers that worked with the students annually discussed how students were progressing through the content and practices in response to their identity and efficacy development. Therefore, the curriculum was designed to monitor the progression of learning across two domains. Within the one domain, we monitored the progression of epistemic agency as evidenced by the construction of a science identity and the development of self-efficacy demonstrated as students engage in student-directed community-oriented activities. Concurrently, within the other domain we monitored the progression of engineering knowledge, skills, and practices. The final learning target was designed to facilitate participation because of an enhanced science identity and self-efficacy that encompasses students developing and using engineering competencies to solve science- or engineering-related problems in their local community of place.

Within this longitudinal mixed methods research study, two quantitative instruments were used along with qualitative methods. Quantitatively, changes in the students' identification as scientists were assessed through the Attitude Toward Science Survey Inventory (ATSI) to measure students' identity as science learners. Quantitatively, changes in students' science and engineering self-efficacy were assessed through the Longitudinal Assessment of Engineering Self Efficacy (LAESE). Annual pre- and post-t tests were conducted and both quantitative surveys to assess changes in identity and efficacy indicated by statistical significance. Quantitative data were analyzed in conjunction with qualitative data. Qualitatively, changes in students' orientation toward science identity, engineering self-efficacy, and epistemic agency in place were assessed through open-ended semistructured interviews. Using a constant comparative approach (Corbin \& trass, 2008), the analysis began with open coding, in which patterns were identified. The patterns were organized into categories. The categories were organized into themes representing students' movement in their learning toward agency, demonstrating the target progression in the highest anchor. The quantitative and qualitative data were analyzed to develop entry, 
intermediate, and target anchors within the learning progression. The research questions for the study that informed the learning progression were as follows:

1. What are the factors influencing the development of epistemic agency of African-American students in the development of an epistemic learning progression?

2. How did these factors translate into the development of an epistemic learning progression?

\section{Development of participatory anchors within epistemic learning progression}

The quantitative data regarding their attitude toward science and engineering efficacy and the qualitative data from the semi-structured interviews were used to design an engineering-oriented place-based learning progression with an epistemic focus around community agency. The learning progression encompassed three anchors that were designed to explore how students progressed toward epistemic agency as they develop their science identity and self-efficacy in engineering (refer to Table 1, ASP place-based learning progression).

Because epistemic agency encompasses students participating and taking ownership during the knowledge building process (Damsa et al. 2010), we examined how students exhibited epistemic agency within the engineering activities. Epistemic agency fosters full participation and ownership during the knowledge building process (engineering activities); thus, we explored the development of a science identity, which enabled them to identify as a member within the science and engineering community. Because knowledge is constructed in the science and engineering community, we examined students' perceptions regarding their capacity to make contributions as a function of their perceptions of selfefficacy during various engineering activities. Science identity and self-efficacy as a function of epistemic agency were analyzed across all three anchors.

The objective of the entry anchor was to develop students' epistemic agency by influencing and enhancing their science identity and self-efficacy through their participation in engineering activities. The engineering activities within this anchor were designed to develop students conceptual understanding of engineering design while encouraging them to examine and consider their engineering practices within the activities in relation to scientist and engineers. At the beginning of the anchor, student responses indicated that they had limited prior knowledge and experiences with STEM. During the interviews, some of the student responses were as follows: Student 1: "I never knew anything about STEM, but I like playing with computers and technology." Student 2: "I have some knowledge about engineering, but I do not have any skills. I do not know how to apply engineering to real world situations." From the quantitative and qualitative data, an entry anchor was designed to cultivate the construction of a science identity and produce engineering activities that would develop their sense of self efficacy in relation to them being able to use engineering practices with inquiry-based activities. Within the entry anchor, all engineering activities centered the contributions of African-Americans in STEM while soliciting the interest of students to explore what contributions they would like to make in STEM. This anchor also presented the agency of African-American scientists and engineers which allowed them to examine how science and engineering solutions were designed to solve problems within their communities. These engineering activities facilitated participation as students 


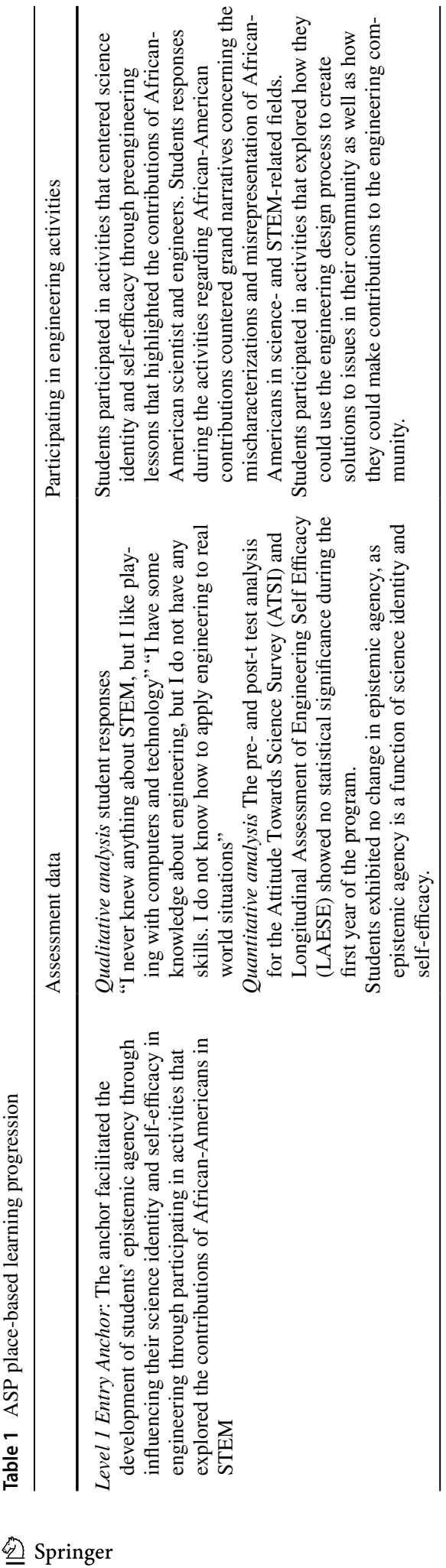




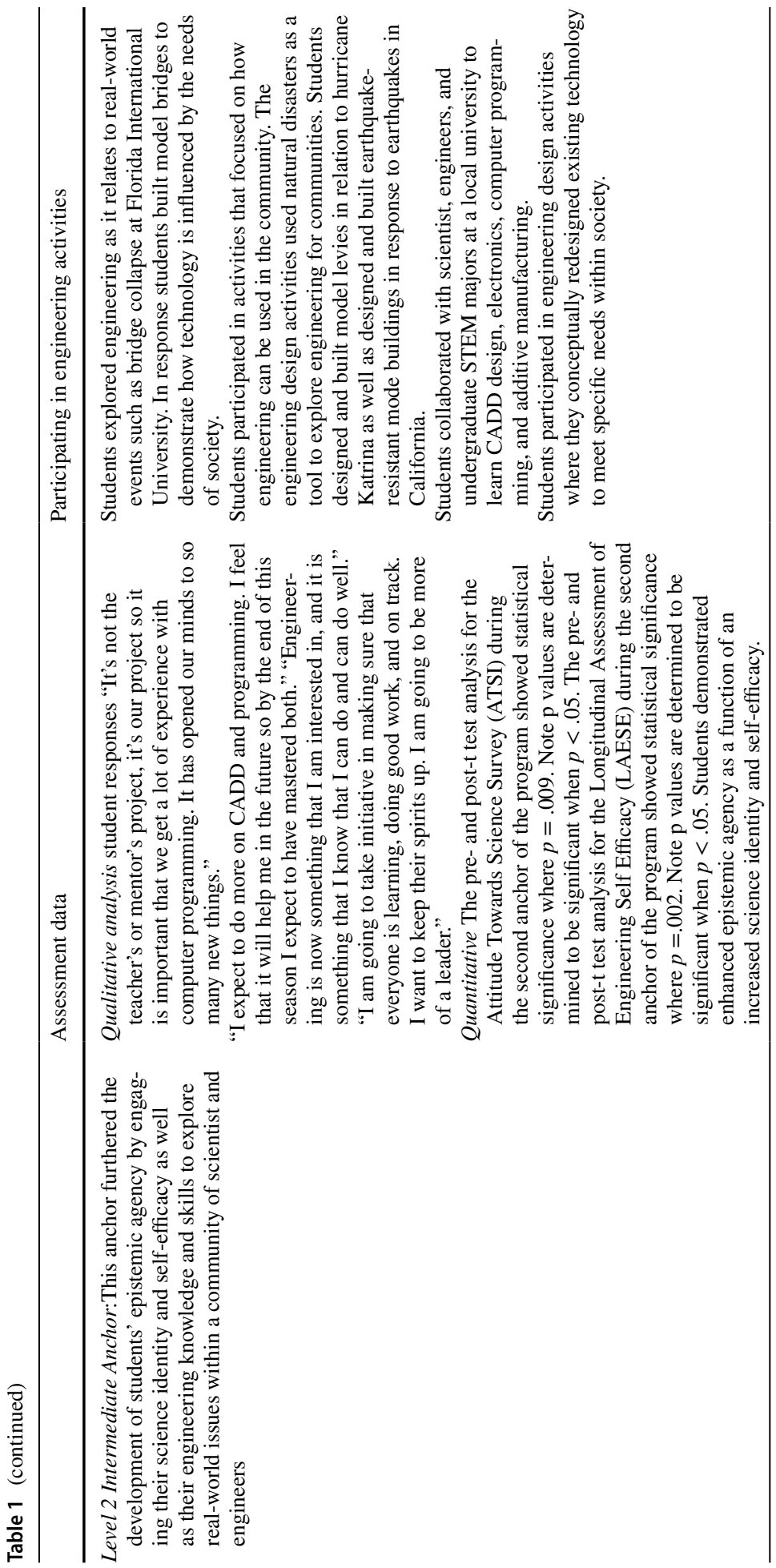




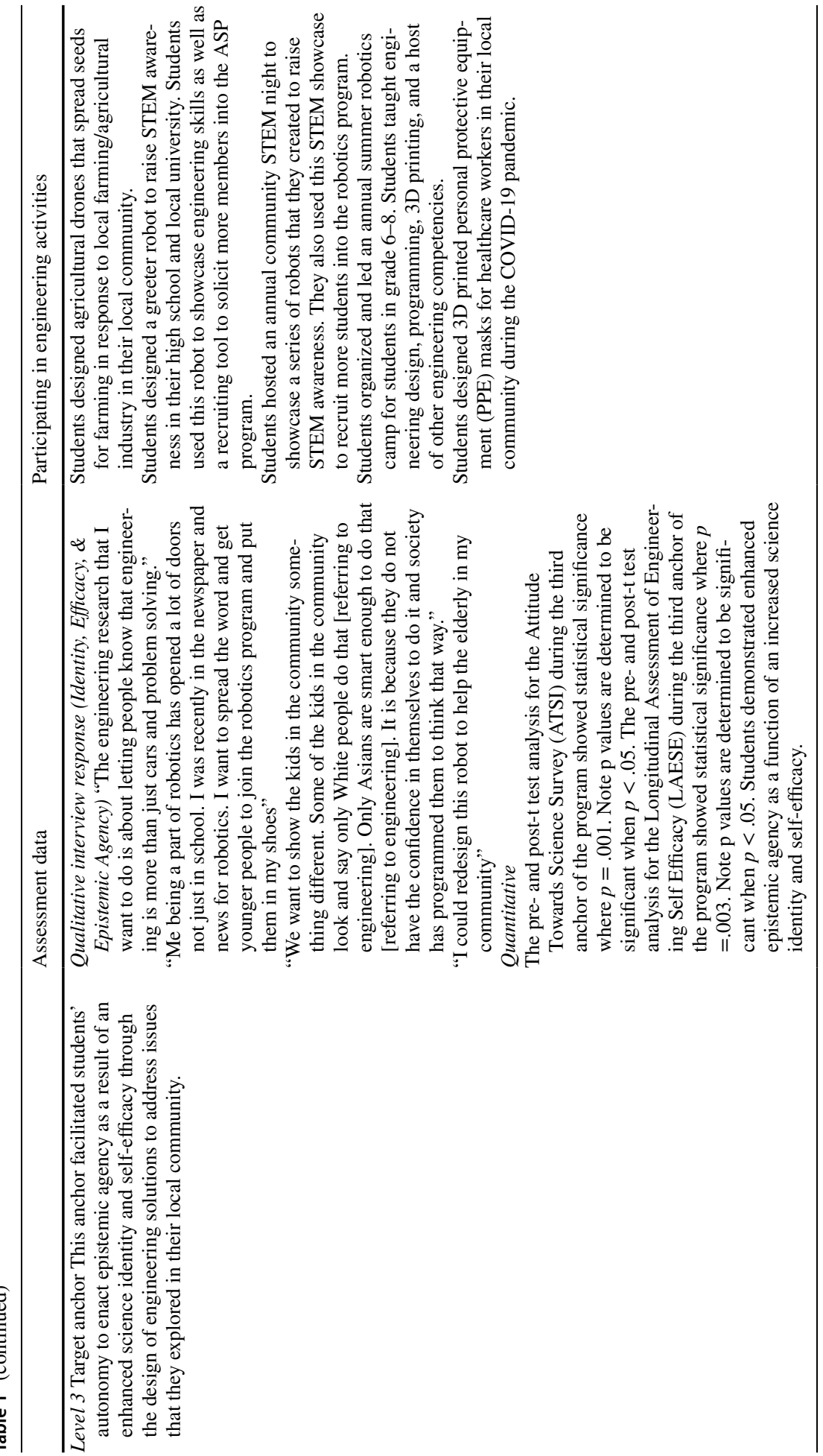


were engaged in a community of practice within the classroom. At the conclusion of this anchor, students were actively engaged in vocalizing what type of innovative contributions they could make in STEM fields which denoted a sense of enhanced identity and efficacy. This anchor was important in that students demonstrated a transformation of the self in which they saw themselves as a member within the STEM community. Quantitatively, at the close of the anchor the students denoted no statistical significance across the ATSI and the LAESE survey. While there was no statistical significance quantitatively, student interviews indicated that their perceptions of themselves had changed as they experienced engineering activities.

The objective of the second anchor was designed to enhance students' epistemic agency by engaging their science identity and self-efficacy as well as their engineering knowledge and skills to explore real-world issues within a community of scientist and engineers. In this anchor, students began to express an enhanced science identity and self-efficacy as well as epistemic agency in which they actively participated with a sense of ownership during the knowledge building process. In an open interview, one of the students was asked about the expectations around learning that he set for himself, "I expect to do more on CADD and programming. I feel that it will help me in the future so by the end of this season I expect to have mastered both." During an open interview, another student stated, "Engineering is now something that I am interested in, and it is something that I know that I can do and can do well." From the collaborative discussions with the team of local scientist, educators, and researchers regarding how the students were progressing in the entry anchor, an intermediate anchor was designed to advance students beyond simply identifying with a community of practice within their classrooms to having them participate in a community of practice with local scientists and engineers. In this intermediate anchor, a new community of practice was established in which students worked directly with local scientists, engineers, and undergraduate STEM majors from a historically African-American university. The engineering activities in this anchor were designed to stimulate epistemic participation and agency as they examined how engineers used their knowledge, skills, and practices to solve real-world problems in their community while provoking the students to explore their own epistemic capacity and participation within their local community.

In the intermediate anchor, students participated in place-based issues that were also relevant to demonstrate what engineers do and what skills and processes are needed to create solutions to community problems. Students participated in a range of activities some of which involved building model bridges in response to the bridge collapse at Florida International University in 2018, designing of earthquake-resistant models in response to the California Ridgecrest earthquakes in 2019, and creating a levee model in response to hurricane Katrina that occurred in 2005. Students discovered what issues existed within their local community as well as explored what could be solved using engineering design knowledge, skills, and practices which served to center their identity and efficacy. This anchor also facilitated students acquiring content knowledge and skills as they engaged in CADD courses, electronic courses, computer programming courses, and additive manufacturing workshops. Within these courses, students collaborated with scientists, engineers, and undergraduate STEM mentors from the local university. By the end of this anchor, students began proposing and creating their own models to solve community issues demonstrating an enhanced identity, efficacy, and agency in that they took ownership in designing solutions using the knowledge that they acquired in this anchor. At the conclusion of the anchor, students quantitatively expressed a change in their science identity and selfefficacy in engineering. Quantitatively, the $\mathrm{p}$ values for both the ATSI and LAESE survey were both $p<0.05$ denoting statistical significance in terms of an enhanced science identity 
and self-efficacy. As students increased expressed an enhanced science identity and selfefficacy in engineering, they also began to increase in their epistemic agency.

Engineering activities for the target anchor were designed to facilitate students' autonomy to enact epistemic agency as a result of an enhanced science identity and self-efficacy through the design of engineering solutions to address issues that they explored in their place-based community. The design of this anchor was developed as a result of further discussions among local scientists, educators, and researchers regarding how students progressed across the intermediate anchor. Thus, the activities in this anchor were designed to advance students beyond their identity and efficacy within the community of practice with scientist and engineers to advancing and providing them with engineering challenges that positioned them to make epistemic contributions within their local community of place. Qualitatively, student responses indicated that they began to advance in their identity, efficacy, and agency as they worked with local scientist and engineers on how engineers solve problems in various communities. As students progressed to and across this anchor their responses indicated that they not only wanted to advance their science identity and sense of self-efficacy for themselves but they also communicated a desire to foster a science identity and advance self-efficacy within their own community as it relates to engineering. During an open interview, one of the students stated, "We want to show the kids in the community something different. Some of the kids in the community look and say only White people do that [referring to engineering]. Only Asians are smart enough to do that [referring to engineering]. It is because they do not have the confidence in themselves to do it and society has programmed them to think that way." Another student began envisioning innovative ways to redesign her existing robot as a function of agency, she remarks, "I could redesign this robot to help the elderly in my community." Within this target anchor students demonstrated their identity transformation and enhanced efficacy in their design of various community-based engineering prototypes. These prototypes demonstrated mastery of both domains within the learning progression. Students continued to use computer programming, electronics, CADD design, and manufacturing to create agricultural drones in response to the local farming industry in the Mississippi Delta. The design of agricultural drones reflected their epistemological development while connecting them to agriculture in which African-Americans in that region have been historically and systemically excluded from. Implementing agricultural concepts in the curriculum reflect (Gruenewald's 2008) concept of reinhabitation in critical pedagogy of place whereby place serves as an opportunity to reposition marginalized communities to participate and, in this case, reclaim enterprises that prioritize hegemonic communities. At the highest level of epistemic participation, students collaborated with the community regarding how to create solutions using the tools of science and engineering for the community.

Students also collaborated with the local university to host an annual STEM showcase in support of building a STEM pipeline from the local high school to the local university. At the showcase, students demonstrated their robots to their mayor, which countered local disassociated images of African-American's achievements in STEM. In addition, the students ran a STEM summer camp for students in grades 3-8. During the STEM summer camp, students designed and taught robotics classes for the younger students which raised STEM awareness in their community. Some of the students who are currently enrolled in the ASP program were previously middle school students that participated in the summer camp. Lastly, students in the program used their knowledge, methods, and practices to 3D manufacture personal protective equipment masks (PPE) for local healthcare workers that did not have enough PPE during the COVID-19 pandemic. At the conclusion of this target anchor, students quantitatively expressed a change in their science identity and self-efficacy 
in engineering. Quantitatively, the p values for both the ATSI and LAESE survey were both $p<0.05$ denoting statistical significance in terms of an enhanced science identity and self-efficacy. As students expressed an enhanced science identity and self-efficacy in engineering, they also began to increase in their epistemic agency.

\section{Reflections and thoughts for future research}

In this response article, we examined and reviewed Ladachart et al.'s place-based learning progressions for northern Thailand. The proposed learning progression discussed in the article, "Toward a hypothetical place-based learning progression for haze pollution in the northern region of Thailand," is a viable approach; however, we offered to extend the discussion by suggesting that place-based learning progressions could move beyond conceptual development to structuring participation in science and participation with local communities. We moved to extend place-based learning progressions to include practiceoriented progressions that facilitated participation as they engaged in disciplinary inquiry. We considered that as students were engaged and continued to progress across a continuum in science and engineering inquiry, students' self-efficacy and science identity were constructed. The constructing of a science identity was paramount to epistemic agency whereby students took ownership of science and engineering to solve problems within their local community. Lastly, we argue that epistemic agency can be actualized through place-based learning progressions if they are designed to address epistemic aims. Therefore, structuring participation within place-based learning progression is an effective way to meet the goals of place-based education that position students to engage in science and engineering practices within local communities.

Structuring epistemic agency as a progression of learning addresses student's positionality while creating a transformational identity that influences participation. Aliza Zivic, John F. Smith, Brian J. Reiser, Kelsey D. Edwards, Michael Novak, and Tara A. W. McGill note that student centered learning that prioritizes students progressing from passive learners to active participants pedagogically facilitates "student's involvement in directing and monitoring knowledge building processes" within their community (Zivic et al. 2018, p.25). Such transformations in response to place-based epistemic-centered learning progressions could be the next step for students to enact disciplinary ownership and science literacy in creating sustainable practices in northern Thailand. In addition, structuring participation within learning progression should include equitable participation in science. Participation in producing knowledge can only be achieved within a framework that facilitates access to epistemic goods such as educational tools and resources, access to a science community and scientists, and quality instructors which are critical components of enhancing the epistemic capacity for designing solutions. The ASP curriculum not only focused on providing the students with content knowledge, but also focused on the ontological transformation of the self from a passive learner to an epistemic agent for their community by providing access to a science and engineering practices and epistemic resources that enhanced their identity and efficacy in engineering.

Grounding the ASP curriculum in enhancing identity development and self-efficacy was key to increasing student achievement in STEM as well as providing meaningful learning experiences that influence students' persistence in STEM. The results of the ASP program echo the work of various researchers in the field. Charles Alvarez et . al. (2010) note that after school or out of school specialty programs are instrumental in providing access to 
STEM which increases academic achievement and raises student interest in STEM fields. Jamaal Young and Jemimah Young's (2018) findings indicate that when African-American students have access to quality enrichment STEM programs, there is a significant effect on their academic performance and other STEM subjects in secondary schools. Further students' dispositions toward STEM through the development of identity and efficacy positively impacts long-term persistence in STEM. Expanding learning progressions so that they include dimensions of social identity transformation can unlock the epistemic capacity of students far beyond the curriculum and can lead to sustained engagement in science- or STEM-related fields.

Lastly, the ASP research has a focus on creating an equitable learning progression to stimulate engagement and participation as they learn science and engineering knowledge and practices. While Corcoran et al. (2009) acknowledge that learning progressions offer equitable potential within this framework, they also note "that here is a need to explore how diversity affects the development and application of learning progressions, and whether, and how progressions can help us close achievement gaps in science" (p.51). This research focused on conducting research with participants that were marginalized and needed an equity-oriented curriculum. In alignment with traditional learning progressions, we desired to develop students' competencies within the discipline for achievement; however, our ultimate goal was to develop their identity and efficacy. Progressing identity and self-efficacy enabled students to envision sustained participation in STEM beyond the temporal dimensions of the learning progressions. The development of identity and selfefficacy also allowed students to actualize their epistemic capacity which enabled become agents of change through the spatial dimensions of place-based education.

Funding Funding was provided by National Foundation for Science and Technology Development (Grant No. 1511792).

\section{References}

Alvarez, C. A., Edwards, D., \& Harris, B. (2010). STEM specialty programs: A pathway for under-represented students into STEM fields. NCSSSMST Journal, 16(1), 27-29. Retrieved from https://files.eric. ed.gov/fulltext/EJ930662.pdf.

Avraamidou, L. (2020). Science identity as a landscape of becoming: rethinking recognition and emotions through an intersectionality lens. Cultural Studies of Science Education, 15(2), 323-345. https://doi. org/10.1007/s11422-019-09954-7.

Bandura, A. (1994). Self Efficacy. In V. S. Ramachaudran (Ed.), Encyclopedia of Human behavior (vol. 4, pp. 7-81). New York, NY: New York Academic Press. Retrieved from https://ebookcentral.proquest. com/lib/vt/detail.action?docID $=863370$.

Bourdieu, P. (1986). The forms of capital. In J. Richardson (Ed.), Handbook of Theory and Research for the Sociology of Education (pp. 241-258). New York: Greenwood.

Bryan, R. R., Glynn, S. M., \& Kittleson, J. M. (2011). Motivation, achievement, and advanced placement intent of high school students learning science. Science Education, 95(6), 1049-1065. https://doi.org/ 10.1002/sce.20462.

Corcoran, T., Mosher, F., \& Rogat, A. (2009). Learning progressions in science: An evidence-based approach to reform. Report of the Center on Continuous Instructional Improvement, Teachers College, Columbia University, New York.

Córdova, R., \& Balcerzak, P. (2016). Co-constructing cultural landscapes for disciplinary learning in and out of school: the next generation science standards and learning progressions in action. Cultural Studies of Science Education, 11(4), 1223-1242. https://doi.org/10.1007/s11422-015-9678-4.

Damsa, C. I., Kirschner, P. A., Andriessen, J. E., Erkens, G., \& Sins, P. H. (2010). Shared epistemic agency: An empirical study of an emergent construct. The Journal of the Learning Sciences, 19(2), 143-186. https://doi.org/10.1080/10508401003708381. 
Duit, R., \& Treagust, D. F. (2012). How can conceptual change contribute to theory and practice in science education?. In B. J. Fraser (Ed.), Second International Handbook of Science Education (vol. 1, no. 24, pp. 107-118). New York. https://doi.org/10.1007/978-1-4020-9041-7.

Duschl, R., Maeng, S., \& Sezen, A. (2011). Learning progressions and teaching sequences: a review and analysis. Studies in Science Education, 47(2), 123-182. https://doi.org/10.1080/03057267.2011. 604476.

Elgin, C. Z. (2013). Epistemic agency. Theory \& Research in Education, 11(2), 135-152. https://doi.org/10. $1177 / 1477878513485173$.

Flowers, A. M., III., Banda, R. M., Bonner, F. A., II., \& Goings, R. B. (2019). An investigation of black males in advanced placement math and science courses and their perceptions of identity related to stem possibilities. Gifted Child Today, 42(3), 129-139. https://doi.org/10.1177/1076217519842213.

Gruenewald, D. A. (2008). The best of both worlds: A critical pedagogy of place. Environmental Education Research, 14(3), 308-324. https://doi.org/10.1080/13504620802193572.

Heritage, M. (2008). Learning Progressions: Supporting Instruction and Formative Assessment. National Center for Research on Evaluation, Standards and Student Testing (CRESST). Retrieved from https:// www.cse.ucla.edu/products/misc/cse_heritage_learning.pdf.

Hofer, B. K. (2006). Domain specificity of personal epistemology: resolved questions, persistent issues, new models. International Journal of Educational Research, 45(1/2), 85-95. https://doi.org/10.1016/j.ijer. 2006.08.006.

Horn, I. S. (2008). Turnaround students in high school mathematics: constructing identities of competence through mathematical worlds. Mathematical Thinking and Learning: An International Journal, 10(3), 201-239. https://doi.org/10.1080/10986060802216177.

Hutchison-Green, M. A. (2008). Why students lose confidence. Asee Prism, 18(2), 61-61. Retrieved March 22, 2021, from http://www.jstor.org/stable/24162984.

Kelly, G. J. (2011). Scientific literacy, discourse, and epistemic practices. In C. Linder, L. Ostman, D. A. Roberts, "P. Wickman, G. Erikson, \& A. McKinnon (Eds.), Exploring the landscape of scientific literacy, (pp. 61-73). New York: Routledge. https://doi.org/10.4324/9780203843284.

Kelly, G. J. (2018). Developing epistemic aims and supports for engaging students in scientific practices. Science \& Education, 27(3/4), 245-246. https://doi.org/10.1007/s11191-018-9974-y.

Kobrin, J. L., Larson, S., Cromwell, A., \& Garza, P. (2015). A framework for evaluating learning progressions on features related to their intended uses. Journal of Educational Research and Practice, 5(1), 58-73. https://doi.org/10.5590/JERAP.2015.05.1.04.

Ladachart, L., Poothawee, M., \& Ladachart, L. (2020). Toward a place-based learning progression for haze pollution in the northern region of Thailand. Cultural Studies of Science Education, 15(4), 991-1017. https://doi.org/10.1007/s11422-020-09981-9.

Lancaster, C., \& Xu, Y. J. (2017). Challenges and supports for african american stem student persistence: a case study at a racially diverse four-year institution. Journal of Negro Education, 86(2), 176-189. https://doi.org/10.7709/jnegroeducation.86.2.0176.

Larsen, T. B., \& Harrington, J. A. (2018). Developing a learning progression for place. Journal of Geography, 117(3), 100-118. https://doi.org/10.1080/00221341.2017.1337212.

Lynn, M. (2004). Inserting the 'race' into critical pedagogy: an analysis of 'race-based epistemologies.' Educational Philosophy and Theory, 36(2), 153-165. https://doi.org/10.1111/j.1469-5812.2004. 00058.x.

Miller, E., Manz, E., Russ, R., Stroupe, D., \& Berland, L. (2018). Addressing the epistemic elephant in the room: epistemic agency and the next generation science standards. Journal of Research in Science Teaching, 55(7), 1053-1075. https://doi.org/10.1002/tea.21459.

NGSS Lead States. (2013). Next generation science standards: for states, by states. Washington, DC: The National Academies Press.

Pierson, A. E., Clark, D. B., \& Kelly, G. J. (2019). Learning progressions and science practices: tensions in prioritizing content, epistemic practices, and social dimensions of learning. Science \& Education, 28(8), 833-841. https://doi.org/10.1007/s11191-019-00070-0.

Smith, G. A. (2007). Place-based education: breaking through the constraining regularities of public school. Environmental Education Research, 13(2), 189-207. https://doi.org/10.1080/13504620701285180.

Smith, J. L., Sansone, C., \& White, P. H. (2007). The stereotyped task engagement process: the role of interest and achievement motivation. Journal of Educational Psychology, 99(1), 99-114. https://doi.org/10. 1037/0022-0663.99.1.99.

Sobel, D. (2004). Place-based education: connecting classrooms and communities. Great Barrington, MA: Orion Society. Retrieved from https://files.eric.ed.gov/fulltext/EJ1183171.pdf. 
Stroupe, D. (2014). Examining classroom science practice communities: How teachers and students negotiate epistemic agency and learn science-as-practice. Science Education, 98(3), 487-516. https://doi.org/ $10.1002 /$ sce. 21112 .

Stroupe, D., Caballero, M. D., \& White, P. (2018). Fostering students' epistemic agency through the co-configuration of moth research. Science Education, 102(6), 1176-1200. https://doi.org/10.1002/sce.21469.

Williams, M. K. (2017). John dewey in the 21st century. Journal of Inquiry and Action in Education, 9(1), 91-102. Retrieved from https://digitalcommons.buffalostate.edu/jiae/vol9/iss1/7.

Woodcock, A., Hernandez, P. R., Estrada, M., \& Schultz, P. W. (2012). The consequences of chronic stereotype threat: Domain disidentification and abandonment. Journal of Personality and Social Psychology, 103(4), 635-646. https://doi.org/10.1037/a0029120.

Yucel, R. (2018). Scientists' ontological and epistemological views about science from the perspective of critical realism. Science \& Education, 27(5/6), 407-433. https://doi.org/10.1007/s11191-018-9983-x.

Young, J., \& Young, J. L. (2018). We can Achieve if We Receive: Examining the Effects of Out-of-School Time Activities on Black Student Achievement in Mathematics. Equity \& Excellence in Education, 51(2), 182-198. https://doi.org/10.1080/10665684.2018.1506952.

Zembylas, M. (2005). Three perspectives on linking the cognitive and the emotional in science learning: Conceptual change, socio-constructivism and poststructuralism. Studies in Science Education, 41, 91-115. https://doi.org/10.1080/03057260508560215.

Zivic A., Smith J.F., Reiser B.J., Edwards K.D., Novak M., McGill T.A.W. (2018). Negotiating epistemic agency and target learning goals: Supporting coherence from the students' perspective. Proceedings of International Conference of the Learning Sciences, ICLS, 1 (2018-June), p. 25-32.

Publisher's Note Springer Nature remains neutral with regard to jurisdictional claims in published maps and institutional affiliations.

Lezly Taylor is a doctoral student in Science Education in the School of Education at Virginia Tech. Her research focuses on the influence of critical pedagogy of place and socioscientific issues on epistemic agency through the development of a science identity for marginalized groups

Brenda Brand is an associate professor in Science Education in the School of Education at Virginia Tech. Her research examines sociocultural factors influencing teaching and learning in STEM disciplines with specific emphasis on marginalized groups 